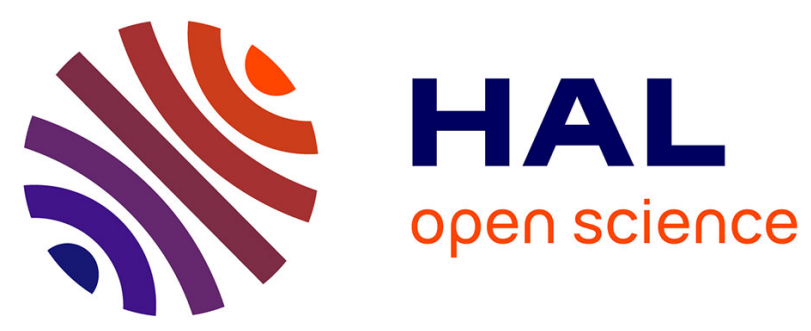

\title{
Dynamic management of water transfer between two interconnected river basins
}

\author{
F. Cabo, K. Erdlenbruch, M. Tidball
}

\section{To cite this version:}

F. Cabo, K. Erdlenbruch, M. Tidball. Dynamic management of water transfer between two interconnected river basins. Resource and Energy Economics, 2014, 37, p. 17 - p. 38. 10.1016/j.reseneeco.2014.03.002 . hal-01006695

\section{HAL Id: hal-01006695 \\ https://hal.science/hal-01006695}

Submitted on 16 Jun 2014

HAL is a multi-disciplinary open access archive for the deposit and dissemination of scientific research documents, whether they are published or not. The documents may come from teaching and research institutions in France or abroad, or from public or private research centers.
L'archive ouverte pluridisciplinaire HAL, est destinée au dépôt et à la diffusion de documents scientifiques de niveau recherche, publiés ou non, émanant des établissements d'enseignement et de recherche français ou étrangers, des laboratoires publics ou privés. 


\title{
Dynamic management of water transfer between two interconnected river basins*
}

\author{
Francisco Cabo $^{\dagger} \quad$ Katrin Erdlenbruch ${ }^{\ddagger} \quad$ Mabel Tidball ${ }^{\S}$
}

20 March 2014

\begin{abstract}
This paper analyzes the dynamic interaction between two regions with interconnected river basins. Precipitation is higher in one river-basin while water productivity is higher in the other. Water transfer increases productivity in the recipient basin, but may cause environmental damage in the donor basin. The recipient faces a trade-off between paying the price of the water transfer, or investing in alternative water supplies to achieve a higher usable water capacity. We analyze the design of this transfer using a dynamic modeling approach, which relies on non-cooperative game theory, and compare solutions with different information structure (Nash open-loop, Nash feedback, Stackelberg) with the social optimum. We first assume that the equilibrium between supply and demand determines the optimal transfer price and amount. We show that, contrary to the static case, in a realistic dynamic setting in which the recipient uses a feedback information structure the social optimum will not emerge as the equilibrium solution. We then study different leadership situations in the water market and observe that the transfer amount decreases towards a long-run value lower than the transfer under perfect competition, which in turn lays below the social optimum. In consequence, the water in the donor's river-basin river converges to a better quality in the presence of market power. Finally, we numerically compare our results to the Tagus-Segura water transfer described in Ballestero (2004). Welfare gains are compared for the different scenarios. We show that in all dynamic settings, the longrun transfer amount is lower than in Ballestero's static model. Further, we show that the long-run price settles at a lower level than in Ballestero's model, but is still higher than the average cost-based price determined by the Spanish government.
\end{abstract}

Keywords: inter- basin water transfer; differential game; Nash equilibrium; non-cooperative game; feedback strategies; bilateral monopoly; Stackelberg game; Tagus-Segura river- basin.

${ }^{*}$ The authors have been partially supported by MEC under projects ECO2008-01551/ECON, ECO2011204352 and by JCYL under project VA001A10-1, which are all co-financed by FEDER funds. The authors also acknowledge financial support from the ANR project RISECO, ANR-08-JCJC-0074-01, and the FP7 project NoviWam.

${ }^{\dagger}$ IMUVa, Universidad de Valladolid, Spain.

${ }^{\ddagger}$ Irstea, UMR G-EAU, 361 rue Jean Francois Breton, 34196 Montpellier cedex 5, France. Tel: +33 467046387. E-mail: katrin.erdlenbruch@irstea.fr (Corresponding author.)

${ }^{\S}$ INRA, UMR Lameta, Montpellier, France. 


\section{Introduction}

This paper analyzes the interaction between two neighboring regions with different water inflows and water productivity. If the river-basin in one region receives more rainfall while the water productivity is higher in the other (for example: higher fertility of the irrigated soil, or demand for water for highly productive activities like tourism), then the existence of a transfer infrastructure that enables the transfer of water from the former to the latter would increase overall productivity (see for example Dinar and Wolf 1994). ${ }^{1}$ Independently of whether the two river-basins are located in the same or in two adjacent countries, using such an aqueduct to transport the water from the donor to the recipient would help increase efficiency, and can therefore be regarded as a good decision (by a central government) or agreement (between the two parties), from an economic point of view.

Because water inflows in the donor basin are large, after covering the demands from households and industrial activity in this region, there will be a water surplus. As long as the water transfer does not exceed the water surplus, it will not harm the donor's economy. Nevertheless, the water transfer reduces the water level in the donor's river-basin, causing environmental degradation, and hence reducing the welfare of the donor. The water transfer improves productivity in the recipient basin but also increases the environmental constraint in the donor basin (for environmental effects of water transfers, see, for example Kumar (2006)). A transfer payment must thus be set up to compensate the donor for forgone benefits from holding on to the water resource.

The payment of the water transfer can be settled by a central planner (who has to determine how to share the gains from cooperation), or through a bargaining process between the two regions which may take place in a water market. Although some kind of cooperation is needed between the regions to set up the market (see Bhaduri et al. 2011), we consider that each region acts non-cooperatively within the market and hence we use non-cooperative game theory to explain the strategic interactions occurring (for a literature review on different non-cooperative solution concepts in game theory see Maduri (2010) and Maduri and Hipel (2011)). We first investigate the Nash equilibrium that occurs in the market (see Nash 1951). We consider a bilateral monopoly with a single water seller and a single water buyer, like in Lekakis (1998). The transfer price will be determined in a demand-supply setting in the market (see for example Ballestero (2004)). Alternatively, we study the solution when one of the players can make a take-it-or-leave-it offer to its counterpart, which is represented in a Stackelberg game. In this case, the price and quantity of the transfer is not determined by the market clearance. The donor (resp. the recipient) chooses the price in order to maximize welfare taking into account the demand for water (resp. the supply of water) made by its opponent. In the following, we will refer to the player who makes the take-it-or-leave-it offer as the player who has the "market power".

Addressing water scarcity through inter-basin water transfer is just one possibility for the recipient. Water-savings, water recycling, or the production of fresh water by desalination plants are alternative ways to increase the supply of usable water that should be considered when long-term decisions concerning water supply are taken. ${ }^{2}$ Each of these three alternatives (water savings, water recycling, water production) requires investment in infrastructure, which gives the problem a dynamic dimension: an intertemporal trade-off between current water transfer payments and investments to increase the usable water capacity. We hence study the problem as a differential game (see Dockner et al. 2000 for an overview on differential games.)

The water transfer from the Tagus basin in the center of Spain to the Segura basin in

\footnotetext{
${ }^{1}$ Water trade between two regions is mutually beneficial when one region is characterized by a relatively less binding water constraint and the other by a relatively efficient water-use technology, see [8].

${ }^{2}$ In a case study in south-eastern Spain Bravo et al. (2010) affirm that the best supply oriented policy is a combination of inter-basin water transfer and desalination.
} 
south-eastern Spain is a good illustration. ${ }^{3}$ While the Segura basin is an arid area with low precipitation and high evapotranspiration, the Tagus basin is more humid. The productivity of water also differs between the two regions. If irrigated, the fertility of the soil in southeastern Spain is very high. In addition, the region receives many tourists thus increasing the demand for water. The imbalance between water productivity and rainfall led the Spanish central government to built a $230 \mathrm{~km}$ network of canals, aqueducts and tunnels to transfer water from the Tagus to the Segura basin. As a result of the transfer, the water quality in the Tagus basin has deteriorated, leading the regional government in the Tagus basin to complain about the transfer, triggering a national political debate on alternatives like desalination plants. Our model considers these three main features: the use of an existing aqueduct, environmental degradation in the donor basin, and the possibility of investing in the equipment required for alternative sources of water supply.

Most of the literature refers to water-share by two neighboring countries: the country located upstream and the country located downstream. For an overview of these studies see Ambec and Ehlers (2008), Ambec and Sprumont (2002), Bhaduri and Barbier (2008), Bhaduri et al. (2011) or Kilgour and Dinar $(1995,2001)$. These models seek efficient water sharing agreements that allow the downstream country to compensate the upstream country for using more water. In our paper, we consider a water-transfer between regions which are not in an up-stream/downstream configuration. If the donor-region does not agree to set-up the transfer, no water reaches the recipient region. An inter-basin water transfer system has in common with the river-sharing models the price charged by the donor for the water transferred to the recipient. However, with an inter-basin water transfer, the two regions face very different environmental constraints. In particular, the transfer only decreases the water level in the donor river, which faces the highest environmental restriction. ${ }^{4}$

Moreover, our model differs in several aspects from the standard literature: In our model, the recipient is able to invest in alternative water supplies, which gives the model a dynamic dimension. The dynamic interaction between donor and recipient is analyzed as a deterministic ${ }^{5}$ differential game with an infinite time horizon. Contrary to the standard formulation, with player-specific decision variables, here the two regions decide on the amount of water to be transferred. The donor (resp. the recipient) decides on the supply (resp. the demand) of water transferred as a function of its price. The equilibrium of this bilateral monopoly will determine the price and quantity of the transfer.

Another characteristic of our model is the coexistence of a static donor and a dynamic recipient who faces an intertemporal dilemma between paying the price of the water transfer or investing in improving the usable water capacity of his/her region. For such a game, we prove that the supply (as a function of price) and demand (as a function of usable water and price) for water transfer do not differ when we change from open-loop players, who commit to a certain path of actions at the start of the game, to more realistic feedback players who can constantly adjust their behavior to the available information concerning the capacity of usable water. However, a feedback recipient is aware of the negative relation between usable water capacity and the price of the transfer. This gives the recipient an incentive to invest more in water infrastructure, and hence demand less water from the donor and pay a lower price for it.

\footnotetext{
${ }^{3}$ Other examples of inter-basin water transfer already in operation or in the planning stage can be found in the literature (see, for example, Bhaduri and Barbier (2008)). Transfers can be set up within the same country (e.g. the Snowy River Scheme in Australia, the Sï $i \frac{1}{2}$ o Francisco Interlinking Project in Brazil, the Olmos Transfer Project in Peru, the South-North Water Transfer Project in China, or the Archeelos Diversion in Greece), or between countries (e.g. from the Kosi in Nepal to the Ganges in India and Bangladesh, or the Lesotho Highlands Water Project between Lesotho and South Africa, to mention just a few).

${ }^{4}$ Here, we ignore the environmental damage that the water transfer could cause to the recipient region. Such effects are reported by Cox (1999), Elvira and Almodï $\frac{1}{2} \operatorname{var}(2001)$, or Gupta and Zaag (2008) and references therein.

${ }^{5}$ To address this problem, we do not focus on inter-annual and intra-annual variations in hydrological resources, which can be modeled with stochastic models (see Ballestero (2004)).
} 
In either case, with or without commitment, the existence of an aqueduct to transport water from donor to recipient at a market price makes both players better off. A static analysis would ignore the recipient's dynamic dilemma faced with having to choose between current water transfer payments or investments in water infrastructure. In this setting, the decentralized and the social optimum coincide. But this result is usually not valid in a dynamic setting. ${ }^{6}$ Our model has the particularity that the open-loop solution in the non-cooperative dynamic game is also Pareto efficient. However, without an institution to enforce the commitment, a feedback recipient invests more in usable water capacity, demands less water and pays a lower price than is socially optimal. ${ }^{7}$ Thus, in a dynamic setting, concluding on Pareto efficiency would be misleading.

Because regions may have different power to influence the market price we also depart from perfect competition and study the Stackelberg solutions of the game when either the donor or the recipient acts as the leader. In this case, the incentive to invest in the capacity of usable water is the highest when the donor fixes a high price for the water transfer, and the lowest when it is the recipient who chooses a low price for the water transfer.

For the case study of the Tagus-Segura transfer, Ballestero (2004) determines the quantity and price of the water transfer by simulating the stochastic supply and demand curves in a static approach. After calibrating the model, we compare our results with those of Ballestero. Having the opportunity to invest in usable water capacity reduces the recipient's dependence on water transfer and, hence, less water is transferred in the long-run. This effect is stronger under feedback strategies, when players do not commit to follow open-loop strategies at the beginning of the game. Likewise, the long-run market price in the competitive market is lower than in Ballestero's model. If the price were not settled in a perfectly competitive market,it would be higher/lower if the power to make a take-it-or-leave-it offer is in the hands of the donor/recipient. In either case the transfer is lower than under perfect competition and hence, it causes a lower environmental damage.

The paper is organized as follows. In Section 2, we present the welfare functions for the donor and the recipient as well as the dynamics of the capacity of usable water. In Section 3, we solve the differential game under open-loop and feedback information structures. We then compare the results for the decentralized solutions with or without commitment. In Section 4, we prove that the two players are better off when they can bargain on the price and quantity of the water transfer than under the case of no transfer. In Section 5, we describe the social optimum and prove that although the static non-cooperative solution is Pareto efficient, this is not the case for the dynamic non-cooperative solution under feedback strategies. Section 6 presents the Stackelberg solutions. In Section 7, we compare our results with those in Ballestero (2004) using numerical simulations. Finally, in Section 8 we present our conclusions.

\footnotetext{
${ }^{6}$ A well known example was given in the early work Lancaster (1973), who showed that capitalism is dynamically inefficient when confronted with the social optimum which could be achieved if workers and capitalists acted together.

${ }^{7}$ Such an institution could involve a future market for water, as suggested by an anonymous reviewer. Even if water could be purchased in advance contingently on investment, a contract mechanism on investment would be needed to attain the social optimum.
} 


\section{The model}

In this section, we describe the dynamic interaction between a region with higher precipitation (donor) and a region with higher water productivity (recipient).

\subsection{The Donor}

The river-basin in the donor region is characterized by relatively high precipitation rates and relatively low productive uses, which creates the conditions for the existence of a water surplus. An inherent characteristic of water inflows and outflows is their randomness. The intensity and the duration of rainfall events or of snow melt are irregularly distributed over the year. Likewise, water needs for irrigation or household water use vary during the year and even at times of day. Nevertheless, developed countries have managed to reduce the impact of periods of drought by building dams in the head of the rivers, which help to maintain the water level of the river stable. Nearly all interbasin water transfer projects include such infrastructure (UNESCO (1999)) that allows the river authority to release more water when the demand is higher and inflows are lower (and vice versa). Here we make the extreme assumption that, with no water transfer, the water surplus, or the water level in the river after covering demands, remains constant over time. Hence, we define $R$ as the maximum possible water surplus in the river without the risk of exhausting the reservoir.

The water stored in the dam can be released into the local river, or transferred through the aqueduct to the recipient. Let us denote, $\tau(t)$ this transfer. Henceforth, the water transfer reduces the surplus or the water level in the river. Because the water demand is already covered, the donor's agriculture, industry or households are not directly affected by the transfer. However, the reduction in the water level in the river reduces the quality of the water, (for example the Tagus basin in Spain collects water from the city of Madrid which means it is important to keep minimum water levels high enough to maintain the dilution capacity of the river). In the following, we assume that the associated environmental problem grows more than linearly ${ }^{8}$ with the amount of water transferred. The environmental amenities or environmental services based on the water level in the river can be represented by:

$$
E(\tau(t))=c\left(R-\frac{1}{2} \frac{\tau(t)^{2}}{R}\right), \quad R, c>0 .
$$

Note that the effect of the water surplus is twofold. Firstly, in the absence of water transfer, environmental amenities increase linearly with the water surplus in the river: $c R$. Secondly, for increments in the water transfer, the marginal reduction in environmental amenities is inversely proportional to this surplus, (while proportional to the share of water transferred): $c \tau(t) / R$. In the following, we assume that environmental amenities and damage are measured in monetary terms.

The donor receives a monetary payment, $p(t)$, from the recipient for each unit of water transferred. The instantaneous welfare function for the donor is then expressed as:

$$
F^{d}(p(t), \tau(t))=E(\tau(t))+p(t) \tau(t)=c\left(R-\frac{1}{2} \frac{\tau(t)^{2}}{R}\right)+p(t) \tau(t) .
$$

\subsection{The Recipient}

If precipitation is low in the river-basin in the recipient region, but water productivity is high, then this region will be willing to pay for the water transferred from the donor. Productive activities in this region (e.g. agriculture or tourism) also depend on other inputs such as labor

\footnotetext{
${ }^{8}$ In fact, although not included in the model, an excessively low level might be an irreversible catastrophe (see for example Tsur and Zemel (1995), (2004)).
} 
or capital. Nevertheless, to focus on the effect of available water on production activities, we consider them as fixed inputs. There are two different quantities of water used in the recipient region: a fixed amount available in the recipient's own river-basin, and a variable quantity transferred by the donor, $\tau(t)$. Additionally, the recipient has an alternative way of increasing the volume of available water. He/she could invest in the equipment required to either save water by reducing water use or water leakage from the distribution network, or by increasing recycling (use of gray water), or by producing water (for example by desalination plants, Merett (1997)). We combine these three possibilities in a single variable, $x(t)$, defined as the capacity to produce, recycle or save water using existing equipment (in the following usable water capacity). It is measured in cubic meters. Capacity increases with new investments and decreases with depreciation:

$$
\dot{x}(t)=s(t)-\delta x(t), \quad x(0)=x_{0} \geq 0,
$$

where $\delta>0$ is the depreciation rate and $s(t)$ is the investment to replenish and further increase current capacity, i.e. the cubic meters additionally saved, produced or recycled above the current capacity.

In the recipient region, welfare comes from the amount of available water: either water transferred, $\tau(t)$, or the region's usable water capacity, $x(t) .{ }^{9}$ Welfare increases with the amount of available water at a decreasing rate. In addition, investments in new capacity are increasingly costly, so we consider quadratic investments costs. This can reflect both the existence of increasing transaction costs and the incremental cost of successive projects to produce, save or recycle water. Finally, instantaneous welfare decreases with transfer payments made to the donor. Hence, the welfare function of the recipient is expressed by:

$$
\begin{aligned}
& F^{r}(p(t), \tau(t), x(t), s(t))=Q(\tau(t), x(t))-p(t) \tau(t)-C(s(t)) \\
& =d\left(\tau(t)+x(t)-\alpha \frac{(\tau(t)+x(t))^{2}}{2}\right)-p(t) \tau(t)-\beta \frac{s(t)^{2}}{2}
\end{aligned}
$$

with $d, \alpha, \beta>0$.

The assumptions of linear-quadratic production and quadratic cost can be perceived as too simplistic or with a limited applicability to reflect reality. Due to their analytic simplicity these are common assumptions in the literature on differential games (see for example Bhaduri et al. 2011, Dockner and Long 1993, Dockner et al. 2000, Negri 1989). While they collect the fundamental ideas of a diminishing marginal productivity and an increasing marginal cost, they also give the game a linear-quadratic structure which makes possible to find analytic solutions.

\section{The Nash game}

In this section, we present the dynamic interaction between the donor and recipient regions. The amount and the price of the water transfer are determined from the supply and demand decisions taken by the donor and the recipient respectively. The donor determines the supply of water in order to maximize the stream of welfare discounted at a constant rate, $\rho$, with an infinite time horizon: ${ }^{10}$

$$
\max _{\tau} \int_{0}^{\infty}\left[c\left(R-\frac{\tau^{2}}{2 R}\right)+p \tau\right] e^{-\rho t} d t
$$

Correspondingly, the recipient must decide on the demand for water from the donor and on the investment in usable water capacity, to maximize discounted welfare:

$$
\max _{\tau, s} \int_{0}^{\infty}\left[d\left(\tau+x-\alpha \frac{(\tau+x)^{2}}{2}\right)-p \tau-\beta \frac{s^{2}}{2}\right] e^{-\rho t} d t .
$$

\footnotetext{
${ }^{9}$ Here we disregard the water from the recipient's own river-basin (assumed constant) and focus on these two alternative sources of water.

${ }^{10}$ Here and henceforth time argument is omitted when no confusion can arise.
} 
The recipient is a farsighted player whose maximization problem is subject to the evolution of usable water capacity in (2). By contrast, the donor behaves as a static or myopic player ${ }^{11}$ because the amount and the price of water transfer has no effect on the dynamics of usable water capacity, and because neither the stock nor the investments in usable water capacity influence the donor's welfare.

In contrast to standard differential games, where control variables differ among players, here we consider that both players decide on the amount of water to be transferred from the donor to the recipient. Thus, optimality conditions for problems (4) and (5) give the supply and the demand of water as a function of its price:

$$
\tau^{S}(p)=\frac{p R}{c}, \quad \tau^{D}(p, x)=\frac{d-p}{d \alpha}-x .
$$

The amount and the price of the water transfer at equilibrium are obtained by equating supply and demand, $\tau^{S}(p)=\tau^{D}(p, x)$. This we denote a Nash equilibrium.

$$
\left(p^{N}(x), \tau^{N}(x)\right)=\left(\frac{c d}{Y+c}(1-\alpha x), \frac{d R}{Y+c}(1-\alpha x)\right),
$$

where $Y=R d \alpha$. From this definition, it immediately follows that the water transfer would only take place if the usable water capacity remains below $1 / \alpha$. From (6) it follows that $1 / \alpha$ would be the demand for water transfer at a zero price and for zero usable water capacity. Hence, this amount can be understood as the maximum water requirements of the recipient.

We will assume henceforth that the water surplus in the donor's river-basin suffices to satisfy any possible demand made by the recipient, $R>1 / \alpha$. Thus, we remove any natural water constraint on the transferred amount, and focus on the transfer reward mechanism and how it is affected by the possibility to increase the usable water capacity. ${ }^{12}$ The solution to this problem depends on the information structure of the players. We thus distinguish between the open-loop and the feedback or Markov perfect equilibria. An open-loop information structure assumes that the players only have the knowledge concerning the initial state of the game, $x_{0}$, and commit to follow an optimal path from this point on. Conversely, in a Markov perfect solution, players adapt their decisions by taking into account the state of the game at each point in time, $x(t)$. In the present paper, the donor is a myopic agent, and hence, his/her optimal decision is always given by $\tau^{S}(p)$ in (6). Conversely, the farsighted recipient would act differently in the two solution concepts considered.

\subsection{Open-loop Nash equilibrium}

In this section, we compute the commitment solution for the game described by the optimization problems in (4) and (5), subject to the dynamics of usable water capacity in (2) and the equilibrium condition $\tau^{S}(p)=\tau^{D}(p, x)$. The optimal open-loop solution is described by the Nash equilibrium price and quantity in (7), and the optimal investment in usable water capacity is given by:

$$
s^{\mathrm{OL}}\left(\lambda_{r}^{\mathrm{OL}}\right)=\frac{\lambda_{r}^{\mathrm{OL}}}{\beta},
$$

with $\lambda_{r}^{\text {OL }}$ the costate variable for the recipient associated with $x$.

\footnotetext{
${ }^{11}$ Problem (4) could be written as:

$$
\max _{\tau}\left[c\left(R-\frac{\tau^{2}}{2 R}\right)+p \tau\right] .
$$

${ }^{12}$ The constraint of a water transfer which does not exceed the water surplus could be explicitly included in the analysis for the central planner. However, in the non-cooperative case we would need to define a mechanism to fix the price when the market equilibrium quantity is above the upper bound. Hence the comparison of results between all different scenarios would be extremely dependent on this mechanism.
} 
Further, the system dynamics is described by:

$$
\begin{aligned}
& \dot{x}=\frac{\lambda_{r}^{\mathrm{OL}}}{\beta}-\delta x, \\
& \dot{\lambda}_{r}^{\mathrm{OL}}=(\rho+\delta) \lambda_{r}^{\mathrm{OL}}-\frac{c d}{c+Y}(1-\alpha x) .
\end{aligned}
$$

The optimal time paths for the usable water capacity and its shadow price are:

$$
\begin{aligned}
& x^{\mathrm{OL}}(t)=\left(x_{0}-\bar{x}^{\mathrm{OL}}\right) e^{\phi^{\mathrm{OL}} t}+\bar{x}^{\mathrm{OL}}, \\
& \lambda_{r}^{\mathrm{OL}}(t)=\beta\left[\left(\phi^{\mathrm{OL}}+\delta\right) x^{\mathrm{OL}}(t)-\phi^{\mathrm{OL}} \bar{x}^{\mathrm{OL}}\right],
\end{aligned}
$$

with

$$
\begin{aligned}
& \bar{x}^{\mathrm{OL}}=\frac{d c}{(c+Y) \Lambda+d c \alpha}<\frac{1}{\alpha}, \\
& \phi^{\mathrm{OL}}=\frac{1}{2 \beta}\left[\rho \beta-\sqrt{\Delta^{\mathrm{OL}}}\right]<-\delta, \quad \text { with } \quad \Delta^{\mathrm{OL}}=(\rho+2 \delta)^{2} \beta^{2}+4 \frac{d c \alpha \beta}{(c+Y)} .
\end{aligned}
$$

and $\Lambda=\beta \delta(\rho+\delta)$.

Here and henceforth, we assume that the initial stock of the usable water capacity, $x_{0}$, is lower than its long-run value (for instance, it might initially be zero). Then, since the capacity of usable water at the steady state is lower than $1 / \alpha$, we can guarantee that this capacity always remains below $1 / \alpha$. Consequently, a positive amount of water is transferred at a positive price.

Given the optimal time paths for the state and the costate variables, the time paths for $\tau$, $p$ and $s$ can immediately be obtained from (7) and (8). Their steady-state values are given by:

$$
\bar{p}^{\mathrm{OL}}=\frac{c d \Lambda}{(c+Y) \Lambda+d \alpha c}, \quad \bar{\tau}^{\mathrm{OL}}=\frac{R d \Lambda}{(c+Y) \Lambda+d \alpha c}, \quad \bar{s}^{\mathrm{OL}}=\frac{\delta d c}{(c+Y) \Lambda+d \alpha c} .
$$

\subsection{Feedback Nash equilibrium}

Open-loop solutions present a problem of credibility. With an OL information structure, the recipient, who is the only farsighted agent, commits to an optimal demand path from the start. Given the supply decided by the static donor, the amount and the price of the water transfer are known as functions of time. Why would he/she stick to the strategy he/she originally agreed to in the light of subsequent information (the state of the system at any time)?

Conversely, when the recipient plays feedback, he/she determines the demand by taking the current usable water capacity into account. Thus the demand for water is not a function of time, but a function of the state of the system. Consequently, the equilibrium price and amount of water transfer are state-dependent. We consider this to be a more realistic solution, while the open-loop solution can be regarded as a benchmark scenario, which requires commitment and is more difficult to achieve in practice.

While the static donor behaves in the same way as in the open-loop scenario, the maximization problem for the farsighted recipient can be written as the Hamilton-Jacobi-Bellman(HJB) equation:

$$
\rho V_{r}^{\mathrm{F}}(x)=\max _{\tau, s}\left\{d\left[(x+\tau)-\frac{\alpha(x+\tau)^{2}}{2}\right]-p \tau-\beta \frac{s^{2}}{2}+\left(V_{r}^{\mathrm{F}}\right)_{x}^{\prime}(x)(s-\delta x)\right\},
$$

where $V_{r}^{\mathrm{F}}(x)$ is the value function for the recipient. Again, the price and quantity of water transfer at equilibrium are determined from the market-clearing condition $\tau^{S}(p)=\tau^{D}(p, x)$.

Proposition 1 For any differential game between a static and a farsighted player described by:

$$
\max _{\tau}[E(\tau)+p \tau], \quad \max _{\tau, s} \int_{0}^{\infty}[Q(\tau, x)-p \tau-C(s)] e^{-\rho t} d t
$$




$$
\text { s.a.: } \quad \dot{x}=f(s, x), \quad \tau^{D}(p, x)=\tau^{S}(p),
$$

the optimal price and quantity can be written as the same function of the state under the feedback and the open-loop Nash equilibria.

Proof. The optimal supply of water chosen by the static player is characterized by equation $p=-E^{\prime}(\tau)$ regardless of the information structure considered. Moreover, because the amount of water transfer does not affect the dynamics of the usable water capacity, the demand for water transferred is also the same for the open-loop or the feedback solution, and is given by equation: $p=Q_{\tau}^{\prime}(\tau, x)$. Equating supply and demand, the price and the optimal amount of water transfer can be written as the same function of the state.

Thus, the price and the optimal quantity in the feedback Nash equilibrium are again given by (7). Although the expressions of price and quantity as functions of the state are the same under OL and feedback information structures, the usable water capacity may evolve differently. The optimal feedback strategy for the investment in usable water capacity reads:

$$
s^{\mathrm{F}}(x)=\frac{\left(V_{r}^{\mathrm{F}}\right)_{x}^{\prime}(x)}{\beta},
$$

where $\left(V_{r}^{\mathrm{F}}\right)_{x}^{\prime}(x)$ is the marginal value of additional units of the usable water capacity, $x$.

Given the linear-quadratic structure of the problem, we make the conjecture of a quadratic value function: $V_{r}^{\mathrm{F}}(x)=a_{r}^{\mathrm{F}} x^{2} / 2+b_{r}^{\mathrm{F}} x+c_{r}^{\mathrm{F}}$. Taking into account the optimal values of $\tau, p$ and $s$, the dynamics of the usable water capacity, (2), and solving the associated Ricati system of equations, we obtain the time path of the usable water capacity as:

$$
x^{\mathrm{F}}(t)=\left(x_{0}-\bar{x}^{\mathrm{F}}\right) e^{\phi^{\mathrm{F}} t}+\bar{x}^{\mathrm{F}},
$$

with

$$
\begin{aligned}
& \bar{x}^{\mathrm{OL}}<\bar{x}^{\mathrm{F}} \equiv \frac{c d(c+2 Y)}{\Lambda(c+Y)^{2}+d c \alpha(c+2 Y)}<\frac{1}{\alpha} \\
& \phi^{\mathrm{F}} \equiv \frac{1}{2 \beta}\left[\rho \beta-\sqrt{\Delta^{\mathrm{F}}}\right]<\phi^{\mathrm{OL}}<-\delta, \quad \text { with } \quad \Delta^{\mathrm{F}}=(\rho+2 \delta)^{2} \beta^{2}+4 \frac{d c \alpha \beta(2 Y+c)}{(c+Y)^{2}} .
\end{aligned}
$$

Again, because we assume $x_{0}<\bar{x}^{\mathrm{OL}}$ then $x(t)<\bar{x}^{\mathrm{OL}}<\bar{x}^{\mathrm{F}}<1 / \alpha$ and as a consequence $\tau^{\mathrm{F}}(t), p^{\mathrm{F}}(t)>0, \forall t>0$. Knowing the time path of the usable water capacity allows the amount and the price of water transfer to be computed, while the coefficients of the value function are:

$$
\begin{gathered}
a_{r}^{\mathrm{F}}=\beta\left(\delta+\phi^{\mathrm{F}}\right)=\frac{(\rho+2 \delta) \beta-\sqrt{\Delta^{\mathrm{F}}}}{2}, \quad b_{r}^{\mathrm{F}}=\frac{d c(c+2 Y)}{(c+Y)^{2}\left(\rho-\phi^{\mathrm{F}}\right)}=\frac{2 d c \beta(c+2 Y)}{(c+Y)^{2}\left(\rho \beta+\sqrt{\Delta^{\mathrm{F}}}\right)}, \\
c_{r}^{\mathrm{F}}=\frac{\left(b_{r}^{\mathrm{F}}\right)^{2}}{2 \beta \rho}+\frac{d}{2 \alpha \rho} \frac{Y^{2}}{(c+Y)^{2}} .
\end{gathered}
$$

and their steady-state values are given by:

$$
\bar{p}^{\mathrm{F}}=\frac{d c \Lambda}{\Lambda(c+Y)+d c \alpha \frac{c+2 Y}{c+Y}}, \quad \bar{\tau}^{\mathrm{F}}=\frac{d R \Lambda}{\Lambda(c+Y)+d c \alpha \frac{c+2 Y}{c+Y}}, \quad \bar{s}^{\mathrm{F}}=\frac{c d \delta}{\Lambda \frac{(c+Y)^{2}}{c+2 Y}+d c \alpha} .
$$

\subsection{Comparison between the open-loop and the feedback Nash equilibria}

In this section, we compare the optimal solutions under OL and feedback information structures. When the recipient does not commit at the beginning of the game, but determines the demand for water transfer and the investment in usable water capacity as a function of the existing stock of this capacity, this stock attains a higher value, not only in the long run, but also at any point in time. To obtain a larger stock, investments generally need to be higher. This becomes clear in the long run $\left(\bar{s}^{\mathrm{F}}>\bar{s}^{\mathrm{OL}}\right.$ immediately follows from (15) and (20)), even though we have not proved it at each point in time. 
Proposition 2 If $x_{0}<\bar{x}^{O L}$, then $x^{O L}(t)<x^{F}(t) \quad \forall t>0$.

Proof. Because $\bar{x}^{\mathrm{OL}}<\bar{x}^{\mathrm{F}}$, then $x_{0}<\bar{x}^{\mathrm{OL}}$ ensures $x_{0}<\bar{x}^{\mathrm{F}}$. Further, since $\phi^{\mathrm{F}}<\phi^{\mathrm{OL}}<0$, then $x^{\mathrm{F}}(t)$ converges faster towards a higher steady state value than $x^{\mathrm{OL}}(t)$. Therefore, the proposition follows.

Because the usable water capacity in the recipient basin is greater without commitment, the amount of the water transfer and the price paid for it will be lower.

Proposition 3 If $x_{0}<\bar{x}^{O L}$, then $\tau^{O L}(t)>\tau^{F}(t)$, and $p^{O L}(t)>p^{F}(t) \quad \forall t>0$.

Proof. From Proposition 2, $x^{\mathrm{OL}}(t)<x^{\mathrm{F}}(t) \quad \forall t>0$. And the expressions for the amount of water transfer and its price in (7), as functions of $x$, are valid both under open-loop or feedback information structures. The proposition follows.

Hence, with OL information, the recipient invests less and accepts a higher water transfer at a higher price. With feedback information, the recipient invests more, which leads to a lower transfer amount at a lower price. We can thus anticipate that the OL situation generates a higher payoff for the donor and the feedback situation generates a higher payoff for the recipient.

Proposition 4 The donor's welfare is higher under open-loop than under feedback: $V_{d}^{O L}>V_{d}^{F}$.

Proof. Using (7) we can compute $F^{d}\left(p^{N}(x), \tau^{N}(x)\right)$. The derivative of this function w.r.t. $x$ is negative:

$$
\frac{d F^{d}\left(p^{N}(x), \tau^{N}(x)\right)}{d x}=\frac{c R d^{2} \alpha(-1+\alpha x)}{(Y+c)^{2}}<0,
$$

because $x<1 / \alpha$. Since, by proposition 2 , we know that $x^{O L}<x^{F}$, then we conclude $V_{d}^{O L}>$ $V_{d}^{F}$.

The donor is thus better off playing open-loop.

In the case of feedback, in contrast to the open-loop solution, the recipient does not regard the price as fixed, but is aware of the negative relationship between the price and the usable water capacity, $p^{\prime}(x)<0$ (assuming an affine decreasing function $p^{\prime}(x)$ would be constant). For a Hamiltonian that considers this feedback effect, the shadow price of the usable water capacity would decrease faster and towards a higher long-run value. ${ }^{13}$

A feedback information structure gives the investment in usable water capacity an addedvalue. Because the recipient knows to what extent the price decreases with an increase in usable water capacity, he invests more and manages to buy water at a lower price. Necessarily, the recipient is thus better off when his/her decisions are linked to the stock of usable water capacity.

We can illustrate this with a numerical example. We ran $10^{5}$ iterations in which the parameters were drawn randomly from a uniform distribution, with $\delta \in[0.001,0.5], \rho \in[0,0.5]$, $R, d, \alpha \in[0.001,1]$ and all other parameters in $[0,1]$. In all cases, we assumed $x(0)=0$. In all cases where the transfer was feasible, i.e. smaller than the maximum possible surplus in the water $(\tau<R)$, it was better for the recipient to play feedback than open-loop: $V_{r}^{\mathrm{OL}}\left(x_{0}\right)<V_{r}^{\mathrm{F}}\left(x_{0}\right)$.

\section{No water transfer}

In this section, we analyze the optimal investment in usable water capacity either in absence of an aqueduct to transfer the water, or assuming that the players decide not to transfer water.

${ }^{13}$ Indeed, the feedback Nash solution could be alternatively computed using the Hamiltonian. It would read:

$$
H^{\mathrm{F}}=d\left[(x+\tau)-\alpha \frac{(x+\tau)^{2}}{2}\right]-p(x) \tau-\beta \frac{s^{2}}{2}+\mu(a s-\delta x) .
$$


With no water transfer, the donor would not face any optimization problem, while the recipient would choose to invest in usable water capacity to maximize:

$$
\max _{s} \int_{0}^{\infty}\left[d\left(x-\alpha \frac{x^{2}}{2}\right)-\beta \frac{s^{2}}{2}\right] e^{-\rho t} d t
$$

subject to $(2)$.

Proposition 5 With no water transfer, the investment in usable water capacity, its stock and its shadow price are given by: ${ }^{14}$

$$
\begin{aligned}
& s^{N T}\left(\lambda_{r}^{N T}\right)=\frac{\lambda_{r}^{N T}}{\beta}, \\
& x^{N T}=(t)=\left(x_{0}-\bar{x}^{N T}\right) e^{\phi^{N T}} t+\bar{x}^{N T}, \\
& \lambda_{r}^{N T}(t)=\beta\left[\left(\phi^{N T}+\delta\right) x^{N T}(t)-\phi^{N T} \bar{x}^{N T}\right],
\end{aligned}
$$

with

$$
\begin{aligned}
& \frac{1}{\alpha}>\bar{x}^{N T} \equiv \frac{d}{\Lambda+d \alpha}>\bar{x}^{F}>\bar{x}^{O L} \\
& \phi^{N T} \equiv \frac{1}{2 \beta}\left[\rho \beta-\sqrt{\Delta^{N T}}\right]<\phi^{F}<\phi^{O L}<0, \quad \Delta^{N T}=(\rho+2 \delta)^{2} \beta^{2}+4 \alpha \beta d,
\end{aligned}
$$

being $\lambda_{r}^{N T}$ the shadow price of the usable water capacity when no transfer is possible.

The usable water capacity is highest when no transfer occurs between the two river-basins. Furthermore, because the speed of convergence is the fastest at this scenario, the stock of usable water capacity is also the highest at any time, $t$. Solving this problem using the HJB equation, with value function $V_{r}^{\mathrm{NT}}(x)=a_{r}^{\mathrm{NT}} x^{2} / 2+b_{r}^{\mathrm{NT}} x+c_{r}^{\mathrm{NT}}$, the coefficients are given by:

$$
a_{r}^{\mathrm{NT}}=\beta\left(\delta+\phi^{\mathrm{NT}}\right)=\frac{(\rho+2 \delta) \beta-\sqrt{\Delta^{\mathrm{NT}}}}{2}, \quad b_{r}^{\mathrm{NT}}=\frac{d}{\rho-\phi^{\mathrm{NT}}}=\frac{2 d \beta}{\rho \beta+\sqrt{\Delta^{\mathrm{NT}}}}, \quad c_{r}^{\mathrm{NT}}=\frac{\left(b_{r}^{\mathrm{NT}}\right)^{2}}{2 \beta \rho} .
$$

In what follows it is proved that both regions are better off when an aqueduct exists and is used to transfer water from the supplier to the recipient.

Proposition 6 If $x_{0}<\bar{x}^{O L}$ the donor would be better off playing feedback Nash than under the no water transfer scenario, $V_{d}^{N T}(x)<V_{d}^{F}(x)$.

Proof. The donor's instantaneous welfare playing Nash surpasses its welfare without water transfer if and only if:

$$
\left.F^{d}\left(p^{\mathrm{N}}\left(x^{\mathrm{F}}(t)\right)\right), \tau^{\mathrm{N}}\left(x^{\mathrm{F}}(t)\right)\right)>F^{d}(0,0) \equiv c R .
$$

That is,

$$
-c \frac{\tau^{\mathrm{N}}\left(x^{\mathrm{F}}\right)^{2}}{2 R}+p^{\mathrm{N}}\left(x^{\mathrm{F}}\right) \tau^{\mathrm{N}}\left(x^{\mathrm{F}}\right)>0 .
$$

Under assumption $x_{0}<\bar{x}^{\mathrm{OL}}$, it holds that $x^{\mathrm{F}}<1 / \alpha$ and then $\tau^{\mathrm{N}}>0$. Hence the condition above can be written as:

$$
p^{\mathrm{N}}\left(x^{\mathrm{F}}\right)>c \frac{\tau^{\mathrm{N}}\left(x^{\mathrm{F}}\right)}{2 R} .
$$

That is:

$$
\frac{c d}{Y+c}\left(1-\alpha x^{\mathrm{F}}\right)>\frac{c}{2 R} \frac{d R}{Y+c}\left(1-\alpha x^{\mathrm{F}}\right) \Leftrightarrow 1>\frac{1}{2} .
$$

\footnotetext{
${ }^{14}$ Superscript NT refers to the case of no transfer.
} 
If the instantaneous welfare of the donor is greater at any time, then the aggregate discounted welfare would also be greater. We hence have $\left.F^{d}\left(p^{\mathrm{N}}\left(x^{\mathrm{F}}(t)\right)\right), \tau^{\mathrm{N}}\left(x^{\mathrm{F}}(t)\right)\right)>F^{d}(0,0) \Rightarrow$ $V_{d}^{\mathrm{F}}(x)>V_{d}^{\mathrm{NT}}(x)$.

The monetary payment to the donor for the water transfer more than offsets the reduction in the environmental amenities caused by the decrease in the water level in the donor's river. The only requirement is that the usable water capacity in the recipient basin is initially below its long run value.

Proposition 7 If $x_{0}<\bar{x}^{O L}$ the recipient is better off playing feedback Nash than under the no water transfer scenario, $V_{r}^{N T}(x)<V_{r}^{F}(x)$.

Proof. The instantaneous payoff for the recipient if it behaves optimally in absence of an aqueduct is: $F^{r}\left(0,0, x^{\mathrm{NT}}(t), s^{\mathrm{NT}}(t)\right)$.

Let us assume that the recipient continues with the investment $s^{\mathrm{NT}}(t)$, and hence with the usable water capacity $x^{\mathrm{NT}}(t)$, but now an aqueduct allows the transfer of water, for which the price is settled playing $\ddot{i} i \frac{1}{2}$ la Nash. Then, the variation in its instantaneous utility with a marginal increment in the amount of water transfer would be:

$$
F_{\tau}^{r}=d\left(1-\alpha\left(x^{\mathrm{NT}}+\tau\right)\right)-p(\tau)-p^{\prime}(\tau) \tau, \quad \text { where } \quad p(\tau)=p^{S}(\tau)=\frac{c \tau}{R} .
$$

And it can be easily derived that:

$$
F_{\tau}^{r}>0 \Leftrightarrow \tau<\frac{d R}{2 c+Y}\left(1-\alpha x^{\mathrm{NT}}\right)
$$

Assumption $x_{0}<\bar{x}^{\mathrm{OL}}$ implies $x^{\mathrm{NT}}<1 / \alpha$, and starting with no water transfer $(\tau=0)$, the above condition always holds for initial increments in $\tau$. The instantaneous welfare increases with a marginal increment in water transfer at any point in time. Consequently, playing the optimal strategy that the recipient would choose if an aqueduct did not exist, $s^{N T}(t)$, and setting $\tau=0$ is not optimal. The recipient can do better by marginally increasing the amount of water transferred.

$$
\exists \hat{\tau}>0 \mid W\left(x_{0}, 0, s^{\mathrm{NT}}(t)\right)<W\left(x_{0}, \hat{\tau}, s^{\mathrm{NT}}(t)\right),
$$

where $W\left(x_{0}, \tau(t), s(t)\right)=\int_{0}^{\infty} F^{r}(\tau(t), p(t), x(t), s(t)) e^{-\rho t} d t$, with $\dot{x}(t)=s(t)-\delta x(t), x(0)=x_{0}$.

When the recipient plays Nash, he/she chooses the demand of water transfer and the investment to maximize $W\left(x_{0}, \tau(t), s(t)\right)$ subject to (2) and the equilibrium condition between supply and demand. Therefore, it must hold that:

$$
W\left(x_{0}, \tau^{\mathrm{F}}(t), s^{\mathrm{F}}(t)\right) \geq W\left(x_{0}, \hat{\tau}, s^{\mathrm{NT}}(t)\right)>W\left(x_{0}, 0, s^{\mathrm{NT}}(t)\right) .
$$

Playing Nash gives a higher payoff to the recipient than not to play.

Through a numerical analysis identical to the one carried out to compare the value functions under open-loop and feedback strategies, for $10^{5}$ iterations, we can confirm that in all cases where the transfer was feasible, it was better for the recipient to play rather than to stick to the no water transfer strategy, $V_{r}^{\mathrm{NT}}\left(x_{0}\right)<V_{r}^{\mathrm{F}}\left(x_{0}\right)$. In fact, we found that the value function for the recipient and for the leader without water transfers was smaller than their value function either under open-loop or feedback information structures: $V_{i}^{\mathrm{NT}}\left(x_{0}\right)<\min \left\{V_{i}^{\mathrm{OL}}\left(x_{0}\right), V_{i}^{\mathrm{F}}\left(x_{0}\right)\right\}, i \in\{r, d\}$.

\section{Social optimum}

In the particular case in which the donor and the recipient are located in the same country, a central government might decide on the amount of water to be transferred and the investment in usable water capacity in the recipient region. In the social optimum a central planner seeks to 
maximize the net present value of joint welfare, through the infinite time horizon and discounted at rate $\rho$ :

$$
\begin{aligned}
& \max _{\tau, s} \int_{0}^{\infty} e^{-\rho t}\left[c\left(R-\frac{\tau^{2}}{2 R}\right)+d\left[(x+\tau)-\alpha \frac{(x+\tau)^{2}}{2}\right]-\beta \frac{s^{2}}{2}\right] d t, \\
& \text { s.a.: } \dot{x}=s-\delta x, \quad x(0)=x_{0} .
\end{aligned}
$$

The amount of water transferred and the investment in usable water capacity for the central planner are:

$$
\tau^{\mathrm{C}}(x)=\frac{d R}{c+Y}(1-\alpha x), \quad s^{\mathrm{C}}\left(\lambda^{\mathrm{C}}\right)=\frac{\lambda^{\mathrm{C}}}{\beta},
$$

where $\lambda^{\mathrm{C}}$ is the shadow price of $x$ for the central planner. And the system dynamics is described by the system of differential equations:

$$
\begin{aligned}
& \dot{x}=\frac{\lambda^{\mathrm{C}}}{\beta}-\delta x, \\
& \dot{\lambda}^{\mathrm{C}}=(\rho+\delta) \lambda^{\mathrm{C}}-\frac{c d}{c+Y}(1-\alpha x) .
\end{aligned}
$$

The equilibrium for $\tau^{\mathrm{C}}$ and $s^{\mathrm{C}}$ coincide with the expressions in (7) and (8) under open-loop. Likewise, the dynamics of the state and the costate variables are identical to their dynamics in (9) and (10) under open-loop. Consequently, $\lambda^{\mathrm{C}}(t)=\lambda^{\mathrm{OL}}(t), x^{\mathrm{C}}(t)=x^{\mathrm{OL}}(t), \tau^{\mathrm{C}}(t)=\tau^{\mathrm{OL}}(t)$ and $s^{\mathrm{C}}(t)=s^{\mathrm{OL}}(t), \forall t \geq 0$. The investment in, the stock and the shadow price of the usable water capacity, as well as the amount of water transfer, are identical under a central authority or assuming decentralized players following open-loop strategies. The social optimum coincides with the Nash open-loop solution, except that there is no monetary payment for the water transfer under a social planner solution. The commitment Nash solution is then Pareto efficient.

There are two main characteristics of the game that lead to the equivalence between openloop Nash and cooperation:

- The optimal decision on water transfer does not influence the dynamics of the state of the system (i.e. the usable water capacity). There is neither a direct effect nor an indirect effect through $s$ (i.e. $\dot{x}$ and $s^{\mathrm{OL}}$ are independent of $\tau$ ).

- The stock or the investments in usable water capacity do not directly affect the donor's welfare $\left(F^{d}(p, \tau)\right.$ is independent of $x$ and $\left.s\right)$.

Proposition 8 For any differential game between a static and a farsighted player described by:

$$
\begin{gathered}
\max _{\tau}[E(\tau)+p \tau], \quad \max _{\tau, s} \int_{0}^{\infty}[Q(\tau, x)-p \tau-C(s)] e^{-\rho t} d t, \\
\text { s.a.: } \dot{x}=f(s, x), \quad \tau^{D}(p, x)=\tau^{S}(p),
\end{gathered}
$$

the non-cooperative open-loop solution coincides with the solution of the problem for the central planner:

$$
\begin{gathered}
\max _{\tau, s} \int_{0}^{\infty}[E(\tau)+Q(\tau, x)-C(s)] e^{-\rho t} d t, \\
\text { s.a.: } \quad \dot{x}=f(s, x) .
\end{gathered}
$$

Proof. Under open-loop Nash, water transfer (market clearance) and investments are characterized by:

$$
p=-E^{\prime}(\tau)=Q_{\tau}^{\prime}(\tau, x), \quad C^{\prime}(s)=\lambda_{r}^{\mathrm{OL}} .
$$


Correspondingly, water transfer and investments for the central planner come from the equations:

$$
E^{\prime}(\tau)+Q_{\tau}^{\prime}(\tau, x)=0, \quad C^{\prime}(s)=\lambda_{r}^{\mathrm{C}} .
$$

In our formulation, the equivalence between the marginal cost of investment and the shadow price is equivalent to:

$$
s=\frac{\lambda_{r}^{\mathrm{OL}}}{\beta}=\frac{\lambda_{r}^{\mathrm{C}}}{\beta} .
$$

The amount of water transfer and the investments are therefore described by the same functions of $x$ under the two scenarios.

The system dynamics in the open-loop Nash game also matches the dynamics of the problem for the central planner:

$$
\dot{\lambda}_{r}^{i}=\rho \lambda_{r}^{i}-\left[Q_{x}^{\prime}(\tau, x)+\lambda_{r}^{i} f_{x}^{\prime}\left(\lambda_{r}^{i}, x\right)\right], \quad \dot{x}^{i}=f\left(\lambda_{r}^{i}, x\right), \quad i \in\{\mathrm{oL}, \mathrm{c}\}
$$

therefore, $\lambda_{r}^{\mathrm{OL}}(t)=\lambda_{r}^{\mathrm{C}}(t)$ and $x^{\mathrm{OL}}(t)=x^{\mathrm{C}}(t)$. Consequently, $s^{\mathrm{OL}}(t)=s^{\mathrm{C}}(t)$ and $\tau^{\mathrm{OL}}(t)=\tau^{\mathrm{C}}(t)$.

Open-loop solutions oblige players to follow the optimal strategy decided at the beginning of the game. These types of equilibria are not credible because players might have an incentive to deviate from the committed strategy at any point in time (especially in the case of an infinite time horizon). Unless this commitment could be enforced, rational players would adjust strategies at any time, knowing the state of the game. The recipient would play feedback strategies, linking the demand for water transfer and the investments in the usable water capacity to the actual level of this stock. Its valuation of the capacity of usable water being higher, this would lead to greater investments and lower water transfer. Consequently, without a mechanism to enforce commitment, the non-cooperative solution deviates from Pareto efficiency with over-investment in capacity and a shortfall in water transfer.

The deviation of the non-cooperative solution from the social optimum does not occur if we treated the interaction between the donor and the recipient as a static game. In the static setting, the Nash equilibrium is Pareto efficient (see the Appendix). Thus if we disregard the dynamic aspect of the problem, the model fails to capture the most salient feature of the solution: the possibility to use a feedback strategy in which the recipient takes into account the impact of his/her investments on the price path of the water transfer. Hence, we may mistakenly conclude that the non-cooperative solution is Pareto efficient when it is not.

So far, the non-cooperative solution refers to the equilibrium under a perfectly competitive market. In the next section, we consider different leadership situations. Thus, we study the solutions when one region (either the donor or the recipient) can make a take-it-or-leave-it offer to its opponent.

\section{$6 \quad$ Stackelberg equilibria}

We move apart from the Nash game where both players move simultaneously and consider hierarchical play. One of the players has priority of move over its opponent. We distinguish two cases depending on who takes the role of the leader: the farsighted recipient or the static donor. Alternatively, we may define the Stackelberg leader as the player having market power. This player is in position to make a take-it-or-leave-it offer to its opponent, thereby maximizing its welfare under the demand constraint (for recipient) or the supply constraint (for donor). An additional feature of this type of solution is that the price of the water transfer does not come from the equality between supply and demand. It will be the Stackelberg leader who, knowing the reaction function of its counterpart, chooses the price and consequently the amount of water transfer. 


\subsection{Recipient as Stackelberg leader}

The donor-follower chooses the supply of water transfer solving its static maximization problem in (4). Knowing the supply of water from the donor, $\tau^{S}(p)=p R / c$ in (6), the recipient-leader chooses the optimal price ${ }^{15}$ and the investments. His/her maximization problem can be written as:

$$
\max _{p, s} \int_{0}^{\infty}\left[d\left(\tau^{S}(p)+x-\alpha \frac{\left(\tau^{S}(p)+x\right)^{2}}{2}\right)-p \tau^{S}(p)-\beta \frac{s^{2}}{2}\right] e^{-\rho t} d t
$$

subject to (2).

The optimal strategies for the recipients are:

$$
p^{\mathrm{rL}}(x)=\frac{d c}{2 c+Y}(1-\alpha x), \quad s^{\mathrm{rL}}\left(\lambda_{r}^{\mathrm{rL}}\right)=\frac{\lambda_{r}^{\mathrm{rL}}}{\beta},
$$

with $\lambda_{r}^{\mathrm{rL}}$ the costate variable for the recipient associated with $x$. In consequence, the optimal amount of water transfer reads:

$$
\tau^{\mathrm{rL}}(x)=\tau^{S}\left(p^{\mathrm{rL}}(x)\right)=\frac{d R}{2 c+Y}(1-\alpha x) .
$$

The dynamic system for state and costate variables can be written as:

$$
\begin{aligned}
& \dot{x}=\frac{\lambda_{r}^{\mathrm{rL}}}{\beta}-\delta x, \\
& \dot{\lambda}_{r}^{\mathrm{rL}}=(\rho+\delta) \lambda_{r}^{\mathrm{rL}}-\frac{2 d c}{2 c+Y}(1-\alpha x) .
\end{aligned}
$$

The optimal time paths for the stock, $x$, and the shadow price, $\lambda_{r}^{\mathrm{rL}}$, of the capacity of usable water are then given by:

$$
\begin{aligned}
& x^{\mathrm{rL}}(t)=\left(x_{0}-\bar{x}^{\mathrm{rL}}\right) e^{\phi^{\mathrm{rL}} t}+\bar{x}^{\mathrm{rL}}, \\
& \lambda^{\mathrm{rL}}(t)=\beta\left[\left(\phi^{\mathrm{rL}}+\delta\right) x^{\mathrm{rL}}(t)-\phi^{\mathrm{rL}} \bar{x}^{\mathrm{rL}}\right],
\end{aligned}
$$

with:

$$
\bar{x}^{\mathrm{rL}}=\frac{2 d c}{(2 c+Y) \Lambda+2 d \alpha c}, \quad \phi^{\mathrm{rL}}=\frac{\rho \beta-\sqrt{\Delta^{\mathrm{rL}}}}{2 \beta}<-\delta, \quad \Delta^{\mathrm{rL}}=(\rho+2 \delta)^{2} \beta^{2}+4 \frac{2 d c \alpha \beta}{2 c+Y} .
$$

An initial capacity of usable water $x_{0}<\bar{x}^{\mathrm{OL}}$ would guarantee $x^{\mathrm{rL}}(t)<\bar{x}^{\mathrm{rL}}<1 / \alpha$ and in consequence a positive amount and price of the water transfer at any time $t$. Knowing $x^{\mathrm{rL}}(t)$ and $\lambda^{\mathrm{rL}}(t)$, the optimal time paths for $\tau^{\mathrm{rL}}(t), p^{\mathrm{rL}}(t)$ and $s^{\mathrm{rL}}(t)$ immediately follow from $(24)$ and (25). Their steady states being:

$$
\bar{p}^{\mathrm{rL}}=\frac{\Lambda d c}{(2 c+Y) \Lambda+2 d \alpha c}, \quad \bar{\tau}^{\mathrm{rL}}=\frac{\Lambda d R}{(2 c+Y) \Lambda+2 d \alpha c}, \quad \bar{s}^{\mathrm{rL}}=\frac{2 \delta d c}{(2 c+Y) \Lambda+2 d \alpha c} .
$$

Remark 9 Notice that the donor-follower is a static player. Hence, he/she does not value the stock of water equipment. Because the follower has no costate variable, the leader cannot determine the initial value of this variable. The open-loop Stackelberg solution is time consistent.

\footnotetext{
${ }^{15}$ Equivalently, we might write the supply function as $p=p^{S}(\tau)$. In that case, the recipient would choose the amount of water transfer. Results are the same under both specifications.
} 


\subsection{Donor as Stackelberg leader}

The recipient-follower solves its dynamic problem in (5) subject to (2). The optimal investment and the optimal demand for water transfer read:

$$
s^{\mathrm{dL}}(x)=\frac{\left(V_{r}^{\mathrm{dL}}\right)_{x}^{\prime}(x)}{\beta}, \quad\left(\tau^{D}(p, x)=\frac{d-p}{\alpha d}-x \Leftrightarrow p^{D}(\tau, x)=d(1-\alpha(x+\tau))\right),
$$

with $V_{r}^{\text {dL }}$ the value function of the recipient-follower. Knowing the demand for water transfer made by the recipient, the donor will determine its price. Because the demand for water is a function of the capacity of usable water, now the donor's welfare is affected by the state of the system. Nevertheless, the decision taken by the donor on the price of the water transfer does not have a direct effect on the evolution of the capacity of usable water. In consequence, although concerned with this capacity, since it cannot influence its accumulation, the donor remains a static player, whose maximization problem can be written as:

$$
\max _{p} \int_{0}^{\infty}\left[c\left(R-\frac{\left(\tau^{D}(p, x)\right)^{2}}{2 R}\right)+p \tau^{D}(p, x)\right] e^{-\rho t} d t
$$

The price and the amount of water at the equilibrium can be written as:

$$
\tau^{\mathrm{dL}}(x)=\frac{d R}{c+2 Y}(1-\alpha x), \quad p^{\mathrm{dL}}(x)=\frac{d(c+Y)}{c+2 Y}(1-\alpha x) .
$$

Conjecturing the standard quadratic value functions: $V_{r}^{\mathrm{dL}}(x)=a_{r}^{\mathrm{dL}} x^{2} / 2+b_{r}^{\mathrm{dL}} x+c_{r}^{\mathrm{dL}}$, the dynamics of $x$ reads:

$$
\dot{x}=\frac{a_{r}^{\mathrm{dL}} x+b_{r}^{\mathrm{dL}}}{\beta}-\delta x,
$$

with:

$$
\begin{aligned}
& a_{r}^{\mathrm{dL}}=\frac{(\rho+2 \delta) \beta-\sqrt{\Delta^{\mathrm{dL}}}}{2}, \quad b_{r}^{\mathrm{dL}}=\frac{2 d \beta\left[(c+2 Y)^{2}-Y^{2}\right]}{(c+2 Y)^{2}\left(\rho \beta+\sqrt{\Delta^{\mathrm{dL}}}\right)}, \\
& \Delta^{\mathrm{dL}}=(\rho+2 \delta)^{2} \beta^{2}+4 \frac{d \alpha \beta\left[(c+2 Y)^{2}-Y^{2}\right]}{(c+2 Y)^{2}} .
\end{aligned}
$$

The time path of the stock of water equipment can now be computed:

$$
x^{\mathrm{dL}}(t)=\left(x_{0}-\bar{x}^{\mathrm{dL}}\right) e^{\phi^{\mathrm{dL}} t}+\bar{x}^{\mathrm{dL}}
$$

with

$$
\bar{x}^{\mathrm{dL}}=\frac{d\left[(c+2 Y)^{2}-Y^{2}\right]}{(c+2 Y)^{2} \Lambda+\alpha d\left[(c+2 Y)^{2}-Y^{2}\right]}, \quad \phi^{\mathrm{dL}}=\frac{\rho \beta-\sqrt{\Delta^{\mathrm{dL}}}}{2 \beta}<-\delta .
$$

Again, the assumption $x_{0}<\bar{x}^{\mathrm{dL}}$ guarantees $x^{\mathrm{dL}}(t)<\bar{x}^{\mathrm{dL}}<1 / \alpha$ at any $t \geq 0$. From (30) and (31) it follows the optimal time paths for $\tau^{\mathrm{dL}}(t), p^{\mathrm{dL}}(t)$ and $s^{\mathrm{dL}}(t)$, which remain positive and converge towards:

$$
\begin{aligned}
\bar{p}^{\mathrm{dL}} & =\frac{\Lambda d(c+Y)(c+2 Y)}{(c+2 Y)^{2} \Lambda+\alpha d\left[(c+2 Y)^{2}-Y^{2}\right]}, \quad \bar{\tau}^{\mathrm{dL}}=\frac{R(c+2 Y) \Lambda d}{(c+2 Y)^{2} \Lambda+\alpha d\left[(c+2 Y)^{2}-Y^{2}\right]}, \\
\bar{s}^{\mathrm{dL}} & =\frac{\left[(c+2 Y)^{2}-Y^{2}\right] \delta d}{(c+2 Y)^{2} \Lambda+\alpha d\left[(c+2 Y)^{2}-Y^{2}\right]} .
\end{aligned}
$$




\subsection{Comparing different scenarios}

We compare in this section the competitive outcome with the Stackelberg solutions, assuming that either the donor or the recipient has market power. Non-cooperative results are put in comparison to the open-loop which corresponds to the social optimum.

Proposition 10 At the steady state, $\bar{x}^{O L}<\bar{x}^{r L}<\bar{x}^{F}<\bar{x}^{d L}<1 / \alpha$, and $\phi^{d L}<\phi^{F}<\phi^{r L}<$ $\phi^{O L}<-\delta$. Moreover, if $x_{0}<\bar{x}^{O L}$ then $x^{O L}(t)<x^{r L}(t)<x^{F}(t)<x^{d L}(t) \quad \forall t>0$.

Proof. The comparison of the steady-state values for the capacity of usable water immediately follow from their expressions in (13), (18), (28), and (33). From (11), (17), (26) and (32), and since the convergence to the steady-state among the different scenarios is faster the higher its long-run value, proposition immediately follows.

Proposition 11 If $x_{0}<\bar{x}^{O L}$ then:

1. $s^{O L}(0)<s^{r L}(0)<s^{F}(0)<s^{d L}(0)$ and $\bar{s}^{O L}<\bar{s}^{r L}<\bar{s}^{F}<\bar{s}^{d L}$.

2. $p^{r L}(0)<p^{F}(0)<p^{d L}(0)$ and $\bar{p}^{r L}<\bar{p}^{F}<\bar{p}^{d L}$.

3. (a) $\tau^{r L}(0)<\tau^{F}(0)=\tau^{O L}(0)$ and $\bar{\tau}^{r L}<\bar{\tau}^{F}<\bar{\tau}^{O L}$,

(b) $\tau^{d L}(0)<\tau^{F}(0)=\tau^{O L}(0)$ and $\tau^{d L}(t)<\tau^{F}(t)<\tau^{O L}(t), \quad \forall t>0$.

4. $\left(c \leq Y \Leftrightarrow 0>E^{\prime \prime}(\tau) \geq \frac{\partial^{2} Q}{\partial \tau^{2}}(\tau, x)\right) \Rightarrow \tau^{r L}(t)>\tau^{d L}(t), \forall t \geq 0$.

Proof. Results follow from the expressions of the steady-states and the optimal strategies as functions of $x$ for all variables under the four different scenarios.

When the recipient is the Stackelberg leader, he/she manages to fix a lower price initially and in the long run. In consequence, the incentive to invest in usable water capacity is also lower than in the competitive solution (investment is lower, at least at the beginning and at the steady state). As shown in Proposition 10, the usable water capacity grows lower. In parallel, because the price decreases deeper, the water transfer supplied by the donor at the initial time and in the long run, is also lower.

Assuming conversely a donor-leader he/she charges a higher price both initially and in the long-run, increasing the incentive to invest in usable water capacity. Investment is greater, at least at the beginning and in the long run. Correspondingly, as shown by Proposition 10, a higher investment increases the capacity of usable water higher at any point in time. Because of that, and since the price of the water transfer is generally higher, the recipient demands less water. In consequence, the amount of water transfer is lower at any time.

The usable water capacity is closest to the social optimum when the recipient is the leader (i.e. the transfer is cheap and hence the incentive to invest is low); and most dissimilar when the donor is the leader (i.e. with a high transfer price and investment incentive). A second characteristic of the social optimum is that water is transferred at its highest rate. In this regard, the competitive transfer is closer to the transfer at the social optimum than a solution in which one of the regions has market power. A donor-leader would fix a high price which implies a low demand of water. And a recipient-leader would fix a low price which discourages the supply of water.

Thus, in terms of the usable water capacity, conferring market power to the recipient would lead the capacity much closer to the social optimum than either the competitive market or a donor-leader solutions. In terms of the water transfer, the competitive transfer is closer to the social optimum than the two alternative solutions that confer market power to either the donor or the recipient. Which of these two scenarios with market power is linked to the smallest transfer depends on parameters' values. If the decrement in the marginal gains for the recipient with additional units of water transfer is faster than the increment in the marginal losses for the donor, then the water transfer would be higher when the market power is in the hands of the recipient. The reverse is not true. 


\section{Numerical illustration: the Tagus-Segura transfer}

To illustrate our results, we use the data of the Tagus-Segura water transfer described in Ballestero (2004) ${ }^{16}$ Mean annual surplus ${ }^{17}$ in the Tagus donor basin amounts to 593.67 million $\mathrm{m}^{3}$, mean annual agricultural water needs in the Lorca recipient region amount to 74 million $\mathrm{m}^{3}$. In our model, $R$ is the water surplus in the river, hence $R=593.67$ million $\mathrm{m}^{3}$ and $1 / \alpha$ are the water requirements in the recipient basin, hence $\alpha=1 / 74=0.0135$.

Next, we calibrate our model with respect to Ballestero's static model. Our results will resemble his if we solve the game considering the welfare function for the donor as in (1), while the instantaneous welfare for the recipient is described by:

$$
F^{r}(p, \tau)=d\left[\tau-\frac{\alpha}{2}(\tau)^{2}\right]-p \tau
$$

We choose the missing parameters of the welfare functions in such a way that the transfer and the prices that solve this static game match the values found by Ballestero, i.e. $\tau^{B}=58$ million $\mathrm{m}^{3}$ and $p^{B}=0.46$ dollar US $/ \mathrm{m}^{3}$. This gives the parameter values $c=4.7084, d=2.1275$. We then come back to the dynamic setting and assume the discount rate $\rho=0.001$ and the equipment depreciation rate $\delta=0.1$. Initial usable water capacity is set to zero: $x(0)=0$. In the following, we distinguish the Nash (N) from the Stackelberg (S) game. In the former, we have results for open-loop and feedback equilibria. In the later, we have results for the case where the donor is the Stackelberg leader $(\mathbf{d L})$, and the case where the recipient is the leader $(\mathbf{r L})$.

Given these parameter values, we can solve the dynamic game, depending on the value of $\beta$ (which measures the cost of investment). Let us first consider two extreme cases, namely the case where $\beta=0$ and the case where $\beta$ tends to infinity. Results are illustrated in Table 1.

Table 1: Results for $\beta=0$ and $\beta=\infty$.

\begin{tabular}{|l|cc|c|c|c|}
\hline & \multicolumn{2}{|c|}{$\beta=0$} & \multicolumn{3}{c|}{$\beta=\infty$} \\
\hline & $\begin{array}{c}\text { Nash } \\
(\mathrm{OL}=\mathrm{F})\end{array}$ & $\begin{array}{c}\text { Stackelberg } \\
(\mathrm{dL}=\mathrm{rL})\end{array}$ & $\begin{array}{c}\text { Nash } \\
(\mathrm{OL}=\mathrm{F})\end{array}$ & $\begin{array}{c}\text { Stackelberg } \\
\mathrm{dL}\end{array}$ & $\begin{array}{c}\text { Stackelberg } \\
\mathrm{rL}\end{array}$ \\
\hline $\bar{\tau}$ & 0 & 58 & 0.0077 & 47.6890 \\
$\bar{p}$ & & 0.46 & 1.1927 & 0.3782 \\
$\bar{x}$ & & 0 & 0 & 0 \\
$\bar{\tau}+\bar{x}$ & & 54 & 0.0077 & 47.6890 \\
\hline
\end{tabular}

At zero investment cost $(\beta=0)$, the recipient region would satisfy all his/her water needs by producing, recycling, or saving free water. The water capacity is immediately reached at no cost and as a consequence, no water needs to be transferred. As shown in Table 1, all equilibria coincide in this case, i.e. Nash (open-loop and feedback) equilibria are equal to the Stackelberg equilibria (with either the recipient or the donor having market-power).

Another extreme case would be defined by infinite investment costs. With no alternative sources of water, the recipient can only rely on the water transfer. As a consequence, the static Nash equilibrium coincides with the dynamic Nash equilibria (open-loop or feedback). This is the case studied by Ballestero. As shown in Table 1, for the Nash equilibrium, we find the same transfer amount and the same transfer price as Ballestero. If the donor is entitled with the market power the transfer is almost negligible at a very high price. And conversely, when the recipient is the leader, it settles a price below the competitive price, hence attracting less transfer than in the competitive market.

\footnotetext{
${ }^{16}$ In particular, we use the information on total supply available in the donor region and total demand in the recipient region over the period 1979-1996, see Ballestero (page 84 Table IV).

${ }^{17}$ Surplus is stored water $\left(833.67\right.$ million $\left.\mathrm{m}^{3}\right)$ minus annual water needs in the Tagus basin $\left(240 \mathrm{million}^{3}\right)$.
} 
For intermediate values of investment costs, we can distinguish different types of dynamic games, depending on the information structure and the leadership situation. We illustrate here the case where $\beta=0.8220$, which is the value for which open-loop and feed-back Nash equilibria differ the most. Table 2 gives the steady-state values of transfer amounts, transfer prices and usable water capacity.

Table 2: Results for $\hat{\beta}$ (Values rounded).

\begin{tabular}{|c|cc|cc|}
\hline & \multicolumn{2}{|c|}{ Nash } & \multicolumn{2}{c|}{ Stackelberg } \\
Static & Open-loop & Feedback & $\mathrm{dL}$ & $\mathrm{rL}$ \\
\hline $\bar{\tau}$ & 33.17 & 24.83 & 0.01 & 21.37 \\
$\bar{p}$ & 0.26 & 0.20 & 0.31 & 0.17 \\
$\bar{x}$ & 31.68 & 42.32 & 54.50 & 40.83 \\
$\bar{\tau}+\bar{x}$ & 64.85 & 67.15 & 54.50 & 62.21 \\
\hline$V_{r}$ & 64509.75 & 65605.94 & 61738.58 & 66071.15 \\
$V_{d}$ & 2799666.45 & 2797748.14 & 2797754.57 & 2797096.32 \\
$V_{r}+V_{d}$ & 2864176.19 & 2863354.08 & 2859503.30 & 2863167.46 \\
\hline
\end{tabular}

In all these dynamic cases, we have a positive stock of equipment that enables less water to be transferred at a lower price than in Ballestero's case. Moreover, the four possible solutions differ. The highest transfer would take place if the two regions commit to open-loop strategies (which coincides with the cooperative case): in that case, 33.17 million $\mathrm{m}^{3}$ should be transferred at 0.26 dollar US $/ \mathrm{m}^{3}$ (compared to 58 million $\mathrm{m}^{3}$ at 0.46 dollar $\mathrm{US} / \mathrm{m}^{3}$ when investment is not possible). As stated above, the Nash case without commitment is more plausible to take place in reality, and leads to transfers and prices which are even lower, with 24.83 million $\mathrm{m}^{3}$ at 0.20 dollar US $/ \mathrm{m}^{3}$. The lowest transfer with the highest price would be set up when the donor has market-power. ${ }^{18}$

In Figures 1 and 2 we compare the time paths of the dynamic solutions under different market structures with the solution found by Ballestero. The optimal transfer amounts (prices) are shown in Figure 1 left (right). Under perfect competition the dynamic transfer initially starts above the static transfer but immediately falls below it, tending to the steady-state values described in Table 1, which are greater under cooperation. When the donor has market power the transfer price is initially fixed much higher than the static price, decreasing below the static value but remaining above the perfectly competitive price (either open-loop or feedback). Correspondingly, the water transfer stays the lowest through time. When the recipient is the leader the price of the water transfer remains the lowest through the whole time horizon. This low price positions the amount of water transfer below the quantity transferred under perfect competition although above the amount when the recipient acts as the Stackelberg leader. Figure 2 depicts the optimal paths of usable water capacity. In the feedback case under perfect competition, optimal investments are greater, leading the stock to higher long-run levels than under cooperation. The capacity grows the highest when the donor has the power in the water market. When the market power corresponds to the recipient, the capacity remains below (although very close to) the stock built under perfect competition.

Table 2 also shows welfare gains in the recipient region, welfare gains in the donor region, and joint welfare gains, as expressed by the value function assuming a zero initial usable water capacity, $x(0)=0$. When comparing individual welfare gains, we have:

$$
V_{d}^{\mathrm{OL}}>V_{d}^{\mathrm{dL}}>V_{d}^{\mathrm{F}}>V_{d}^{\mathrm{rL}}, \quad V_{r}^{\mathrm{rL}}>V_{r}^{\mathrm{F}}>V_{r}^{\mathrm{OL}}>V_{r}^{\mathrm{dL}} .
$$

Hence, each player is better off being the Stackelberg leader than playing Nash and is worse off if his opponent is the Stackelberg leader. Commitment is the best scenario for the donor,

\footnotetext{
${ }^{18}$ Sufficient condition in point 4 in Proposition 11 is satisfied, $c \leq Y$.
} 
even better than Stackelberg leadership. By contrast, the recipient has a strong incentive to deviate from the open-loop solution committed at the beginning. With respect to joint welfare, we have:

$$
V^{\mathrm{C}} \equiv V^{\mathrm{OL}}=2864176.19>V^{\mathrm{F}}=2863354.08>V^{\mathrm{rL}}=2863167.46>V^{\mathrm{dL}}=2859503.30 .
$$

Joint welfare is highest when the information structure is open-loop, which corresponds to the social optimum. Moreover, we see that the joint welfare under Nash feedback is closer to the social optimum than in the Stackelberg cases. Hence, if the central government is concerned with the joint welfare for the two regions, perfect competition would be an adequate market structure in the eyes of the central authority. The worst case in terms of joint welfare would be to give the donor the market power. However, if the central government is concerned with environmental problems, it will feel inclined to entitle market power to the donor in order to better preserve the quality of the water in the donor river-basin (maybe excessively, in the example $\tau^{\mathrm{dL}}<<\tau^{\mathrm{F}}$ ). Correspondingly this market structure would induce the recipient to make the highest investment to improve the capacity of usable water $\left(x^{\mathrm{dL}}>x^{\mathrm{F}}>x^{\mathrm{rL}}\right)$.

It is however interesting to notice that a market structure which would give market power to the recipient, paradoxically can help to maintain a better water quality than in the perfectly competitive case $\left(\tau^{\mathrm{rL}}<\tau^{\mathrm{F}}\right)$, while at the same time, the joint welfare is not so strongly reduced as in the case when the market power lies in the hands of the donor as water provider $\left(V^{\mathrm{rL}}>\right.$ $\left.V^{\mathrm{dL}}\right)$.

\section{Conclusions}

In this paper we analyze water transfer between two river-basins connected by an aqueduct. The recipient's region, which benefits from the transfer, agrees to pay the donor for forgone environmental benefits from holding on to the water resource. Our main objective is the optimal determination of price and quantity of the water transfer, which is organized in a market place. We use non-cooperative game theory to mimic the decisions in the market. Inspired from the water transfer from the Tagus to the Segura basin, we analyze different market structures: perfect competition or market power in the hands of either donor or recipient.

The recipient faces a dynamic dilemma as he/she can pay the price of the water transfer or can invest in alternative water supplies; the donor is a myopic agent whose supply decisions disregard this accumulation process. The dynamic interaction between the two regions is analyzed as a differential game. We first consider open-loop and feedback Nash equilibria. In the Nash-game, contrary to standard problems, the two players both decide on the amount of water to be transferred: The donor fixes the supply and the recipient fixes the demand, both as a function of the price. The market clearance condition determines the price and the quantity at equilibrium. Besides, we show that in a fairly general class of games with one myopic player, optimal price and quantity are the same functions of the state under the feedback or the openloop Nash equilibria. In the Stackelberg game, the leader knows the reaction function of his counterpart and hence fixes the price.

One of the main results of our paper is the following: We show that if the interaction between the players is treated as a static game, the non-cooperative solution coincides with the cooperative solution and is then Pareto efficient. Conversely, in a dynamic setting with no mechanism to enforce commitment, the non-cooperative solution is characterized by feedback strategies. The feedback Nash equilibrium does not coincide with the cooperative solution and is therefore not Pareto efficient. Only if the players have no information on the state of the system or their commitment is somehow exogenously enforced, would it be adequate to consider open-loop information structures. And only in that case, the laisser-faire policy would be Pareto efficient. Hence, a dynamic game in which both players have conflicting objectives leads to dynamical inefficiencies. 
More precisely, a feedback recipient is aware of the fact that a greater usable water capacity would reduce the price of the water transfer. Consequently, the recipient invests more in the alternative infrastructure. And hence, the increase in usable water capacity is higher under feedback than under open-loop information structures. This implies that less water is transferred at a lower price. We prove (analytically) that the recipient is better off, while (numerically) the donor is worse off. Since the open-loop solution is Pareto efficient, the aggregate welfare would be higher with a commitment. We further prove that when the price and quantity of the water transfer are optimally chosen, either with or without commitment, both players are better off than in the case of no transfer.

Secondly, we consider a hierarchical mode of play, in with one region is the Stackelberg leader and can make a take-it-or-leave-it offer to his/her opponent, who acts as the follower. When the donor possesses market power, we show that he/she can charge a higher price than in the competitive market, both initially and in the long-run. This increases the incentive for the recipient to invest in usable water capacity (his demand is generally lower), which leads to an even lower transfer amount. Conversely, if the recipient is the Stackelberg leader, we show that he manages to fix a low transfer price, initially and in the long-run. However, because the price is small, the water transfer supplied by the donor is also lower, which leads to a transfer (at the initial time and in the long-run) which is smaller than the competitive transfer. Not surprisingly, the results are not symmetrical to the previous case.

Overall, the water transfer is closest to the social optimum when the two regions play Nash and most dissimilar when the donor is the leader. The usable water capacity is closest to the social optimum when the recipient is the leader and most dissimilar when the donor is the leader. Contrary to the amount of water transfer, the environmental quality is the highest when the donor is the leader and the lowest when the competitive market is in place.

Finally, we compare the price and quantity of water transfer with the supply-demand scheme described in Ballestero (2004). After calibrating the model, we observe that the opportunity to invest in alternative water supplies reduces the recipient's dependence on water transfer: less water is transferred in the long-run and the long-run price is smaller than in Ballestero's model. More precisely, we find that the long-run prices for our dynamic models lie between Ballestero's static market-clearing price and the average cost-based priced proposed by the Spanish government.

From a political viewpoint, the most appropriate water market structure depends on which objective is most relevant for the central government. From a joint welfare perspective a perfectly competitive market would yield the joint welfare closest to the social optimum. However, if the central government is strongly concerned with environmental problems, giving the donor the market power would help to keep the water transfer low and hence maintain water quality in the highest standard. Finally, a market structure in which the recipient possesses the market power could be preferred to perfect competition, since it allows a better water quality at a very low cost in terms of joint welfare. 


\section{Appendix: A static setting}

The recipient can buy water from the donor at a market price or can invest in the creation and maintenance of equipment to save, produce or recycle water, the stock of which we call the usable water capacity. As we have seen, usable water capacity is strategic for the recipient because it allows him/her to influence the market price in the transfer market. Until now, we have assumed that building up this water capacity requires time. In this appendix, we make the simplifying assumption that usable water capacity immediately adjusts to the optimal level, once the investment decision is taken. We also consider that this capacity, once created, never decreases, i.e. that the depreciation rate is zero. These are two unrealistic assumptions but they allow us to transform our dynamic model into a static model so as to compare the results. If both models give the same insights, one might be tempted to rely on the more simple static model, rather than the more complicated dynamic one.

The payoff functions for the two players in the static setting read:

$$
\begin{gathered}
F^{d}(p, \tau)=c\left(R-\frac{1}{2} \frac{\tau^{2}}{R}\right)+p \tau \\
F^{r}(p, \tau, s)=d\left[x+\tau-\frac{\alpha}{2}(x+\tau)^{2}\right]-p \tau-\frac{1}{2} \beta s^{2}, \quad x=x_{0}+s .
\end{gathered}
$$

where $s$ is the investment decision and $x$ the usable water capacity. As before, let us assume that the initial usable water capacity is zero, i.e. $x_{0}=0$, which implies $x=s$ and the recipient's payoff function can be written as:

$$
F^{r}(p, \tau, s)=d\left[s+\tau-\frac{\alpha}{2}(s+\tau)^{2}\right]-p \tau-\frac{1}{2} \beta s^{2} .
$$

The Nash equilibrium for this static game is obtained by maximizing $F^{d}(p, \tau)$ w.r.t. $\tau, F^{r}(p, \tau, s)$ w.r.t. $\tau$ and $s$, and taking into account the market clearing condition to determine the price of the water transfer, $\tau^{S}(p)=\tau^{D}(p, s)$. Correspondingly, the social optimum is obtained by maximizing $F(\tau, s)=F^{d}(p, \tau)+F^{r}(p, \tau, s)$ w.r.t $\tau$ and $s$.

It can be easily seen that the amount of water transfer and the investment in usable water capacity under the Nash equilibrium coincide with the social optimum. Thus, the non-cooperative solution is Pareto efficient. Therefore in this case there is no need for regulation. 


\section{References}

[1] Ambec, S., and Ehlers, L., 2008, Sharing a river among satiable agents, Games and Economic Behavior, 64, 35-50.

[2] Ambec, S., and Sprumont, Y., 2002, Sharing a river, Journal of Economic Theory, 107, 453-462.

[3] Ballestero, E., 2004, Inter-Basin Water Transfer Agreements: A decision Approach to Quantity and Price, Water Resources Management 18: 75-88.

[4] Bhaduri, A., Barbier, E.B., 2008, International Water Transfer and Sharing: The Case of the Ganges River, Environment and Development Economics, 13, 29-51.

[5] Bhaduri, A., Barbier, E., Liebe, J., 2011, Climate change and cooperation in transboundary water sharing: an application of stochastic Stackelberg differential games in Volta river basin, Natural Resource Modeling 24(4), 409-444.

[6] Bravo, M., González, I., García-Bernabeu, A., 2010, Ranking supply oriented policies of water management policies from institutional stakeholders' political views, European Water, $31,43-58$.

[7] Cox, W.E., 1999, Determining when interbasin water transfer is justified: criteria for evaluation, in Interbasin Water Transfer, Proceedings of the International Workshop, IHP-V, Technical Documents in Hydrology No. 28, UNESCO, Paris, 173-178.

[8] Dinar, A. and Wolf, A., 1994, Economic potential and political considerations of regional water trade: The Western Middle East example, Resource and Energy Economics, 16(4), 335-356.

[9] Dockner, E.J., van Long, N., 1993, International Pollution Control: Cooperative versus Noncooperative Strategies, Journal of Environmental Economics and Management, 24, 1329.

[10] Dockner, E.J., Jørgensen, S., van Long, N., and Sorger, G., 2000. Differential Games in Economics and Management Science. Cambridge University Press, Cambridge.

[11] Elvira, B. and Almodóvar, A., 2001, Freshwater fish introductions in Spain: facts and figures at the beginning of the 21st century. Journal of Fish Biology, 59: 323-331. doi: 10.1111/j.1095-8649.2001.tb01393.x.

[12] Gupta, J. van der Zaag, P., 2008, Interbasin water transfers and integrated water resources management: Where engineering, science and politics interlock, Physics and Chemistry of the Earth, 33, 28-40.

[13] Kumar, D., 2006, Environmental impact of inter-basin water transfer projects: some evidence from Canada, Economic and Political Weekly, 17, 1703-1707.

[14] Lancaster, K., 1973, The dynamic inefficiency of capitalism, Journal of Political Economy, 81, 1092-1109.

[15] Lekakis, J.N., 1998, Bilateral Monopoly: a market for intercountry river water allocation, Environmental Management, 22, 1-8.

[16] Madani, K., 2010, Game theory and water resources, Journal of Hydrology, 381(3-4), 225238. 
[17] Madani, K., Hipel, K.W., 2011, Non-cooperative stability definitions for strategic analysis of generic water resources conflicts. Water Resources Management 25, 1949-1977.

[18] Merrett, S., Introduction to the Economics of Water Resources - an international perspective, UCL Press, London 1997, 211p.

[19] Nash, J.F., 1951, Non-cooperative games, Annals of Mathematics 54(2), 286-295.

[20] Negri, D.H., 1989, The Common Property Aquifer as a Differential Game, Water Resources Research 25, 9-15.

[21] Tsur, Y., Zemel, A., 1995, Uncertainty and irreversibility in groundwater resource management, Journal of Environmental Economics and Management, 29,149-161.

[22] Tsur, Y., Zemel, A., 2004, Endangered aquifers: Groundwater management under threats of catastrophic events, Water Resources Research 40, 1-10.

[23] UNESCO, Interbasin Water Transfer: Proceedings of the International Workshop, IHP-V, Technical Documents in Hydrology No. 28, Paris, 1999. 

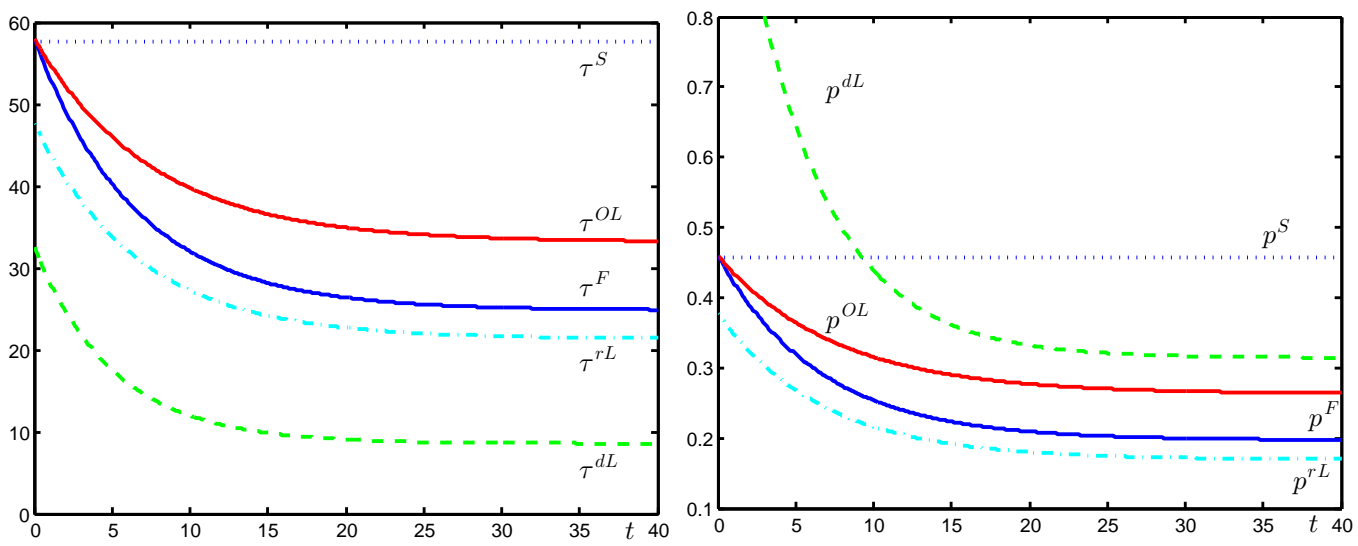

Figure 1: Time paths for transfer quantity and price

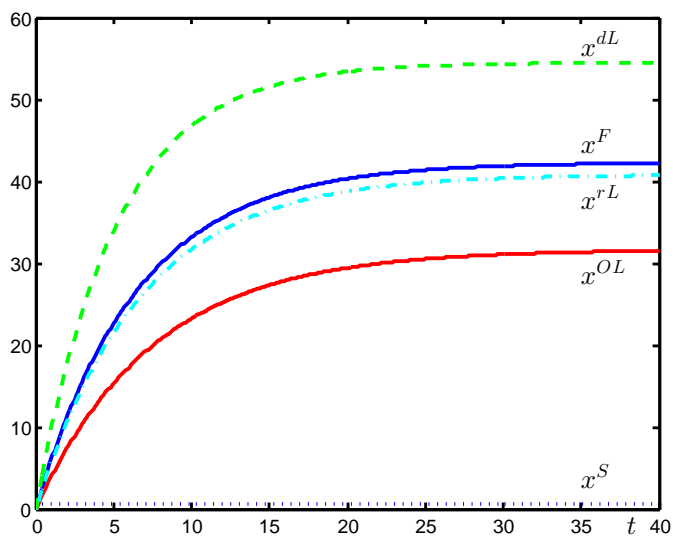

Figure 2: Time paths for usable water capacity 